\title{
Neuroprotective Potential of Dimethyl Fumarate-loaded Polymeric Nanoparticles against Multiple Sclerosis
}

\author{
SMRITI OJHA*, BABITA KUMAR ${ }^{1}$ AND HINA CHADHA
}

Vishveshwarya Group of Institutions, Department of Pharmacy, G. B. Nagar, Noida-203 207, ${ }^{1}$ Sanskar Educational Group, Department of Pharmacy, Ghaziabad-201 302, India

\section{Ojha et al.: Development of Dimethyl Fumarate-loaded Chitosan Nanoparticles}

\begin{abstract}
The aim of the present study was to access the potential of dimethyl fumarate-loaded chitosan polymeric nanoparticles for the management of multiple sclerosis. Dimethyl fumarate-loaded chitosan nanoparticles were prepared by polyelectrolyte complex coaservation technique. The prepared nanoparticles were characterized and found to have an average particle size of $324 \mathrm{~nm}$, zeta potential of $-34.85 \mathrm{mV}$ and a poly dispersity index of 0.367 . The entrapment efficiency was found to be $65.36 \%$ and the drug loading was $28 \%$. The formulation's in vitro drug release profile and stability parameters were also evaluated. Cumulative percent drug release was found to be $84 \%$ up to 24 hours and the formulation was found to be stable at $28^{\circ}$ for 90 days. In vitro neuroprotective effect of the nanoformulation was evaluated using 3-(4,5-dimethylthiazol-2-yl)-2,5-diphenyltetrazolium bromide assay on human neuroblast SH-SY5Y cells and the treated cells showed improved cell viability under hydrogen peroxide-induced cell apoptosis. In vivo cuprizone model for multiple sclerosis in rodents also confirmed these findings by showing a significant increase in locomotion score.
\end{abstract}

Key words: Multiple sclerosis, chitosan nanoparticles, cuprizone model, SH-SY5Y cells, bioavailability

The neurodegenerative process is a key step in the pathogenesis of multiple sclerosis (MS) with symptoms of permanent neurological disability and impairment ${ }^{[1,2]}$. Currently, most available MS therapeutic agents are immunomodulatory or immunosuppressive in nature $^{[3-5]}$ and effectively inhibit immune cell-driven inflammation thus reduce the relapse rate. But they do not control the predominant neurodegenerative processes that mainly occur later in the disease course $^{[6]}$. Dimethyl fumarate (DMF) is a fumaric acid ester that has been used since 1959 for the treatment of psoriasis ${ }^{[7]}$. FDA has now approved DMF as a first line oral treatment for lowering relapse rates in $\mathrm{MS}^{[8-11]}$. DMF and its active metabolite monomethyl fumarate (MMF) have antioxidant property by activation of the transcription factor, nuclear factor-erythroid derived 2 -factor pathways ${ }^{[12-14]}$. Oxidative stress is one of the key factors for neuron degeneration and pathogenesis of MS disease, which is evidenced within MS lesions, and also in experimental autoimmune encephalomyelitis, a mouse model of $\mathrm{MS}^{[15]}$. In last decade, nanotechnology has proved its effectiveness for the diagnosis and treatment of variety of immune-mediated diseases. In the present study, chitosan (CS) dextran sulphate (DS) nanoparticles loaded with DMF were prepared using the polyelectrolyte complex coaservation technique and the nanoparticles' zeta potential and average particle size were measured. CS is a biocompatible, biodegradable, low toxic, cationic polymer with mucoadhesive properties. Polymeric nanoparticulate drug delivery systems offer enhanced penetrating ability of molecules across mucosal surfaces, good systemic availability, targeted drug delivery, improved pharmacokinetic profile, better half-life and drug pay load. Now a days nanotechnology offers a promising results and effective platform for many industrial and medical fields ${ }^{[16,17]}$. The developed CS-DS nanoparticles were further evaluated in vitro in human neuroblastoma SH-SY5Y cells and in an established cuprizone animal model in vivo.

This is an open access article distributed under the terms of the Creative Commons Attribution-NonCommercial-ShareAlike 3.0 License, which allows others to remix, tweak, and build upon the work non-commercially, as long as the author is credited and the new creations are licensed under the identical terms

Accepted 12 April 2019

Revised 23 December 2018

Received 03 September 2018

Indian J Pharm Sci 2019;81(3):496-502 


\section{MATERIALS AND METHODS}

CS (degree of acetylation $=80.45 \%$ ) and DS were procured from Chemsworth Chemicals, Surat. DMF was obtained from Alfa Aesar, a Johnson Matthey Company. Dimethyl sulphoxide (DMSO), 3-(4,5-dimethylthiazol-2-yl)-2,5-diphenyltetrazolium bromide (MTT), Dulbecco's modified Eagle medium, Ham's F12 (DMEM/HF12), fetal bovine serum (FBS), and cuprizone were obtained from Aakaar Biotechnology Pvt. Ltd., Lucknow. Methanol, glacial acetic acid and acetone were of suitable analytical grade. Double-distilled water was used in the preparation of solutions and dispersion of CS nanoparticles.

\section{Preparation of various batches of CS-DS nanoparticles:}

CS-DS nanoparticles were prepared using the polyelectrolyte complex coaservation method ${ }^{[18-20]}$. Solution of CS was prepared by dissolving measured quantity of CS in $2 \% \mathrm{v} / \mathrm{v}$ acetic acid solution and DS solution was prepared by dissolving measured quantity of DS in double-distilled water. The ratio between the volumes of DS and CS solution was kept at 1:4. DS solution was added into CS solution dropwise with vigorous stirring. The concentration range of both the polymer solutions were kept in the range of 1 to $0.125 \% \mathrm{w} / \mathrm{v}$. CS-DS nanoparticle suspension thus formed was stabilized by the addition of $1 \mathrm{ml}$ of Tween 80 and was vortexed at $1200 \mathrm{rpm}$ for further $1 \mathrm{~h}$. All the formulations were prepared at room temperature and in triplicate. Prepared nanoparticles from all the batches were separated by centrifugation at $12000 \mathrm{rpm}$ for about $1 \mathrm{~h}$. The prepared nanoparticle batches were optimized on the basis of their particle size, polydispersity index (PDI) and zeta potential ${ }^{[21,22]}$.

\section{Preparation of DMF-loaded CS-DS nanoparticles:}

Optimum concentrations of CS and DS solutions were prepared to synthesize DMF-loaded nanoparticles. DMF was dissolved in the solution of CS at a concentration of $1 \mathrm{mg} / \mathrm{ml}$. DMF-loaded nanosuspension was separated by centrifugation and the obtained pellets were washed with distilled water, again redispersed in phosphate buffer (pH 6.8).

\section{Characterization of DMF-loaded CS-DS nanoparticles, particle size, PDI and zeta potential:}

DMF-loaded CS-DS nanoparticles were further characterized by determining their average particle size, zeta potential, PDI, entrapment efficiency (\% EE) and in vitro $\%$ cumulative drug release. The average particle size, PDI and zeta potential were measured with a photon correlation spectroscopy Delsa Nano C (Beckman Coulter Counter, USA) particle size analyser. The samples of formulated CS-DS nanoparticles were placed in disposable cuvettes for measuring average particle size and zeta potential. The CS-DS nanoparticles were dispersed in an appropriate volume of high performance liquid chromatography (HPLC) grade water at $25^{\circ}$, at a detection angle of $90^{\circ}$ for measurement of average size and PDI and an angle of $120^{\circ}$ for measuring its zeta potential.

\section{Percent EE:}

The $\%$ EE was calculated as per previously reported procedures. DMF-loaded CS-DS nanoparticles were separated from the colloidal dispersion by ultracentrifugation at $12000 \mathrm{rpm}$ for $1 \mathrm{~h}$. The DMF content in the supernatant was analysed using UV/Vis spectrophotometer at $208 \mathrm{~nm}$. \% EE was calculated using the formula give below ${ }^{[23,24]} . \% \mathrm{EE}=$ (total amount of DMF-free DMF in supernatant)/total amount of DMF added $\times 100$.

\section{In vitro drug release profile:}

In vitro drug release from the DMF-loaded CSDS nanoparticles was determined using the equilibrium dialysis process at $37 \pm 1^{\circ[25,26]}$. Accurate quantity of CS-DS nanoparticles (equivalent to $1 \mathrm{mg}$ DMF) were suspended in $10 \mathrm{ml}$ of phosphate buffer solution (PBS) $\mathrm{pH} 7.4$ and this suspension was placed in a dialysis membrane bag and tied. This CS-DS nanoparticleloaded dialysis membrane bag was then dipped in a beaker with $500 \mathrm{ml}$ PBS, which was stirred at $50 \mathrm{rpm}$ on a magnetic stirrer. Throughout the dissolution experiment, sink condition was maintained by withdrawing $5 \mathrm{ml}$ of the aliquots at regular time intervals and replacing the same volume of fresh PBS after each withdrawal. To separate the polymeric CS-DS nanoparticles, the collected aliquots were than centrifuged at $12000 \mathrm{rpm}$. The $\%$ cumulative DMF release profile was calculated by analysing the released DMF content with the help of UV/Vis spectrophotometer at $208 \mathrm{~nm}$.

\section{Cell culture and MTT assay:}

In vitro neuroprotective potential of DMF-loaded CSDS nanoparticles were determined using the MTT assay $^{[27,28]}$. SH-SY5Y human neuroblastoma cells were seeded in a 96 well plate and maintained at a density of 5000 cells/well. These cells were allowed to grow in DMEM/HF12 medium containing $10 \% \mathrm{v} / \mathrm{v}$ FBS and 
antibiotic/actinomycin solution $(1 \% \mathrm{v} / \mathrm{v})$ for $24 \mathrm{~h}$. To study the neuroprotective effect of DMF-loaded CSDS nanoparticles on SH-SY5Y neuroblastoma cells, hydrogen peroxide $\left(\mathrm{H}_{2} \mathrm{O}_{2}\right)$ was used to induce cell apoptosis ${ }^{[29]}$. Cytotoxicity of $\mathrm{H}_{2} \mathrm{O}_{2}$ towards $\mathrm{SH}-\mathrm{SY} 5 \mathrm{Y}$ cells were tested with freshly prepared $\mathrm{H}_{2} \mathrm{O}_{2}$ solution at concentrations of $0,50,100,200,250$ and $300 \mu \mathrm{M}$. $\mathrm{H}_{2} \mathrm{O}_{2}$ concentration which was able to produce $60 \%$ cell death was selected as an optimum $\mathrm{H}_{2} \mathrm{O}_{2}$ concentration for further study.

\section{Determination of neuroprotective activity of DMF- loaded nanoparticles:}

To observe the neuroprotective potential of DMFloaded CS-DS nanoparticles, cells were treated with different concentrations of DMF-loaded CS-DS nanoparticles $(100,50,25,12.5,6.25,3.125 \mu \mathrm{M})$ for $24 \mathrm{~h}$. Thereafter, the treated cells were kept with an optimum $\mathrm{H}_{2} \mathrm{O}_{2}$ concentration $(250 \mu \mathrm{M})$ to induce cell apoptosis and incubated for another $24 \mathrm{~h}$ followed by adding MTT solution ( $5 \mathrm{mg} / \mathrm{ml}$ in PBS) in each well. The plates were allowed to stand for further $4 \mathrm{~h}$ and formazan crystals formed inside the cells were than solubilized in DMSO. The absorbance of resulting solution was measured at $570 \mathrm{~nm}$ using a microplate reader ${ }^{[30,31]}$.

\section{In vivo studies using cuprizone model for MS:}

In vivo experiments were carried out as per the protocol approved by the Institutional Animal Ethical Committee. Wistar rats (150-200 g) were randomly selected from the institutional animal house and placed at $22 \pm 2^{\circ}$ temperature and $12 \mathrm{~h} \mathrm{light/dark} \mathrm{cycles.} \mathrm{The}$ animals were further divided into 3 groups $(n=6)$. To induce toxic demyelination in rodents, a dose of cuprizone was used between 0.4 to $2 \%$ as reported in previous studies ${ }^{[32-34]}$. In the present research work, $1 \%$ cuprizone dose was given after mixing it with powdered rat chow for a period of $4 \mathrm{w}$ to develop toxic demyelination. The treatment group received DMFloaded CS-DS nanoparticles at a dose equivalent to $50 \mathrm{mg} / \mathrm{kg}$ of DMF orally, from the very first day of study along with cuprizone.

\section{Locomotor activity:}

Spontaneous locomotor activity of rodents was studied with the help of actophotometer. Wistar rats from above 3 groups $(n=6)$ were placed in actophotometer individually and their basal motor behaviour were recorded and compared.

\section{Motor coordination (rotarod test):}

The rotarod test equipment consists of a drum having diameter $7.0 \mathrm{~cm}$ attached with a rod. This rod was rotated with 20 revolutions/min. Rats $(n=6)$ from each group were placed on the rotating rod and the number of falls from the rotating rod was counted individually for $5 \min ^{[35,36]}$.

\section{Open field test:}

Open field test apparatus consisted of a plywood having dimension $72 \times 72 \times 42 \mathrm{~cm}$, and was open from both the sides. The floor of plywood was equally divided into 25 squares. Wistar rats $(n=6)$ from each group were kept at one end of the open field apparatus and number of squares crossed by individual rat in 3 min was counted.

\section{In vivo pharmacokinetic study:}

Rats weighing around $200 \mathrm{~g}$ and 5-6 w old were randomly selected for oral pharmacokinetic experiments. These rats were fed with standard laboratory pellet diet and pure water ad libitum. The rats were divided into two groups $(n=6)$ and first group was treated with pure DMF $(50 \mathrm{mg} / \mathrm{kg}$ ) and the second group was treated with CSDS nanoformulations with a dose equivalent to $50 \mathrm{mg} / \mathrm{kg}$ pure DMF. At predetermined time intervals $0.5 \mathrm{ml}$ blood samples were withdrawn from the retro orbital plexus and mixed with heparin solution to prevent clotting. Plasma was separated by centrifugation from the collected blood samples. The content of both DMF and its active metabolite MMF were determined using reversed-phase-HPLC ${ }^{[37-39]}$.

\section{Stability studies:}

Stability study of CS-DS nanosuspension loaded with DMF was carried out to ensure its future commercial viability. The nanodispersion was packed in amber colored glass bottles and were stored at $2-8^{\circ}$, ambient condition and at $\left(28 \pm 4^{\circ}\right)$ for $90 \mathrm{~d}$. At regular time intervals $(1,30,60$ and $90 \mathrm{~d})$ samples from the stored formulations were withdrawn and their average particle size and residual drug content was analysed. The results of the stability study were subjected to analysis of variance to determine statistical significance $(\mathrm{p}<0.05)$.

\section{RESULTS AND DISCUSSION}

CS and DS are polymers having opposite charges are the basic reason for cross linking. The charge ratios per mole of both the polymers were calculated and effect of this variable on average particle size and 
zeta potential was studied. At a particular weight ratio and calculated charge ratio of both the polymers, total 5 batches of nanoparticles were formulated. The results of z-average, PDI and zeta potential of all the prepared batches are listed in the Table 1. CS and DS both the polymers having opposite charges were used for preparation of polymeric nanoparticles and these particles were stabilized by Tween 80 . Ionotropic gelation method was used to fabricate CSDS nanoparticles. Effect of polymer concentration on particle size was studied and it was observed that as ratio of CS polymer in nanoformulation increases, particle size decreases. In general very small particle size was found with very low ratio of CS:DS. Charge ratio also effects significantly the z-average and zeta potential of formulation ${ }^{[40]}$. It was observed that as charge ratio increases z-average of particle and zeta potential value also increases.

In the present study, CS-DS nanoparticles prepared were characterized and the values of average particle size, PDI and z-average of DMF-loaded CS-DS nanoparticles were found to be $324 \mathrm{~nm},<0.367$ and $-34.85 \mathrm{mV}$, respectively. The $\%$ entrapment efficiency of formulation was calculated to be $65.36 \%$ and the drug loading was found to be $28 \%$. Better entrapment efficiency with a good drug load confirms a good drug carrying capacity of nanoformulation, which is one of most desirable characteristics of CS-DS nanoparticles. TEM microphotograph (fig. 1) also confirmed that the particles are smooth and spherical with nonaggregation ${ }^{[41]}$. Zeta potential value predicts the kinetic stability of colloidal dispersions, which is an indication of balance between attractive and repulsive forces of suspended particles. Colloidal suspensions with zeta potential values less than $-30 \mathrm{mV}$ and more than $+30 \mathrm{mV}$ are generally considered as stable. Thus the present colloidal dispersion with a zeta potential value of $-34.85 \mathrm{mV}$ also possessed a good kinetic stability.

\section{TABLE 1: FORMULATION AND CHARACTERISATION OF VARIOUS BATCHES OD CS-DS NANOPARTCLES}

\begin{tabular}{lccccc}
\hline $\begin{array}{l}\text { Batch } \\
\text { No }\end{array}$ & $\begin{array}{c}\text { Weight } \\
\text { ratio of } \\
\text { CS:DS }\end{array}$ & $\begin{array}{c}\text { Charge } \\
\text { ratio of } \\
\text { Polymers }\end{array}$ & $\begin{array}{c}\text { Particle } \\
\text { Size } \pm \text { SD } \\
(\mathrm{nm})\end{array}$ & PDI \pm SD & $\begin{array}{c}\text { Zeta } \\
\text { potential } \\
\pm S D(\mathrm{mV})\end{array}$ \\
\hline 1 & $5: 5$ & 1.12 & $723 \pm 35$ & $0.847 \pm 0.08$ & $24.12 \pm 1.2$ \\
2 & $5: 2.5$ & 0.57 & $940 \pm 43$ & $0.763 \pm 0.02$ & $32.24 \pm 0.8$ \\
3 & $5: 7.5$ & 1.45 & $514 \pm 21$ & $0.542 \pm 0.03$ & $-19.15 \pm 1.5$ \\
4 & $5: 10$ & 2.25 & $364 \pm 15$ & $0.412 \pm 0.07$ & $-28.4 \pm 2.2$ \\
5 & $5: 20$ & 4.47 & $320 \pm 8$ & $0.367 \pm 0.03$ & $-35.23 \pm 2.4$ \\
\hline
\end{tabular}

CS is chitosan, DS is dextran sulphate, PDI is polydispersity index, SD is standard deviation for $n=3$ observation

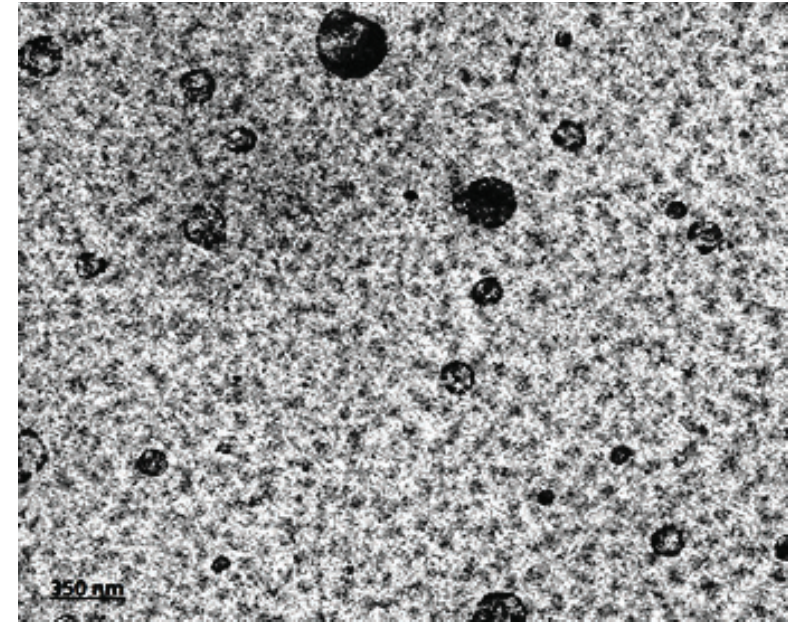

Fig. 1: TEM microphotograph of CS-DS nanoparticles

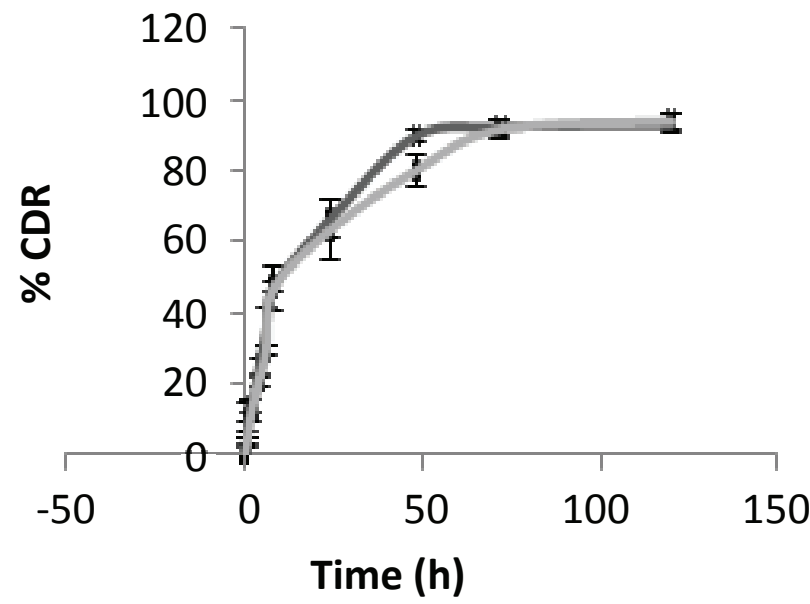

Fig. 2: In vitro drug release profile

(一) Avg (HCl), (-) Avg (PBS), CDR: cumulative drug release

In vitro drug release profile confirmed a sustained release pattern with a $\%$ cumulative drug release of $84 \%$ over a period of $24 \mathrm{~h}$, which is represented in fig. 2.

It was clearly evident from the MTT assay that on SH-SY5Y neuroblastoma cells, cytotoxicity increased with increase in $\mathrm{H}_{2} \mathrm{O}_{2}$ concentration (Table 2). The $\mathrm{H}_{2} \mathrm{O}_{2}$ dose used was $250 \mu \mathrm{M}$, which showed $60 \%$ cell death. Treatment of SH-SY5Ycells with DMF-loaded CS-DS nanoparticles impacted the viability of these cells significantly. There was a significant increase in $\%$ cell viability among treated cells as compared to the cells treated with $\mathrm{H}_{2} \mathrm{O}_{2}$ alone (fig. 3 ). The $\%$ cell viability was increased at different concentrations of pure DMF and DMF-loaded CS-DS nanoparticles. A dose equivalent to $12.5 \mu \mathrm{M}$ had shown maximum cell viability of $85.21 \%$. The DMF-loaded colloidal formulation demonstrated neuroprotective potential in $\mathrm{H}_{2} \mathrm{O}_{2}$-induced SH-SY5Y cell apoptosis. The results of study were analysed and compared by means of 
ANOVA $(\mathrm{p}<0.05)$ and it was found that the cell viability was significantly increased.

Cuprizone is a copper chelator and this agent was used to induce toxic demyelination in rodents ${ }^{[41]}$. The motor behavioural scores, grasping ability and forelimb strength were found to be significantly higher in cuprizone model of Wistar rats after treatment with DMF-loaded CS-DS nanoformulations (Table 3). Decreased number of falls from rotarod also confirms a better grasping ability among treated groups of rats. Similar results were recorded in open field test as treated rats were crossed significantly more number of squares as compared to diseased groups as shown in fig. 4. In vivo study results were evaluated by ANOVA $(\mathrm{p}<0.05)$, which confirms the significant effectiveness of DMF-loaded CS-DS nanoformulation in cuprizone model of Wistar rat for MS.

The oral pharmacokinetic parameters of pure DMF and DMF-loaded CS-DS nanoparticles were calculated and tabulated in Table 4. CS-DS-loaded nanoparticles showed an improved pharmacokinetic profile and the pharmacokinetic values of $\mathrm{C}_{\max }, \mathrm{T}_{\max }$, and area under the curve were found to be significantly higher for DMF-loaded CS-DS nanoparticles, which indicated a faster onset of action and a long absorption phase of the present polymeric colloidal particles. The half-

TABLE 2: EFFECT OF $\mathrm{H}_{2} \mathrm{O}_{2}$ CONCENTRATION ON $\%$ CELL VIABILITY

\begin{tabular}{lc}
\hline $\mathrm{H}_{2} \mathrm{O}_{2}(\mu M)$ & \% Cell viability \\
\hline 0 & 100 \\
50 & 73.2 \\
100 & 63 \\
150 & 66.3 \\
200 & 51.2 \\
250 & 40.5 \\
300 & 31.9 \\
\hline
\end{tabular}

$\mathrm{SD}$ is standard deviation for $\mathrm{n}=3$ observation

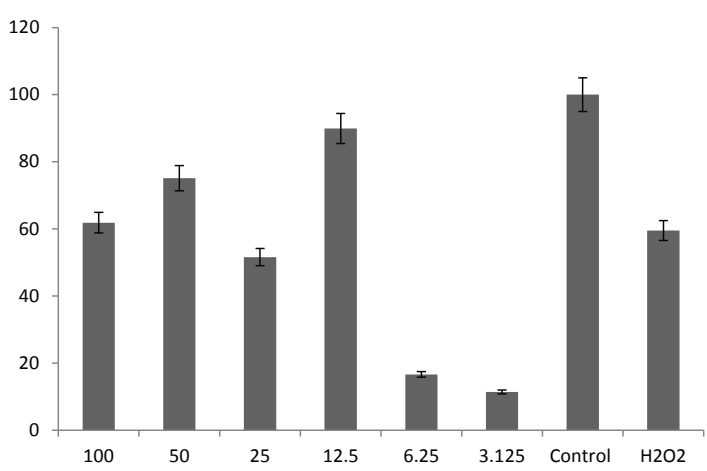

Fig. 3: Effect on DMF concentration on \% cell viability (घ) Cell viability

May-June 2019
TABLE 3: LOCOMOTOR SCORE AND FALL OFF TIME

\begin{tabular}{lcc}
\hline Group & $\begin{array}{c}\text { Locomotor } \\
\text { score } \pm \text { SD }\end{array}$ & $\begin{array}{c}\text { Time to fall from rotating rod } \\
\text { (seconds } \pm \text { SD) }\end{array}$ \\
\hline Control & $195.12 \pm 11.24$ & $112.34 \pm 8.12$ \\
Diseased & $107 \pm 12.36$ & $56 \pm 10.45$ \\
Treatment & $164 \pm 2.45$ & $82 \pm 11.87$ \\
\hline
\end{tabular}

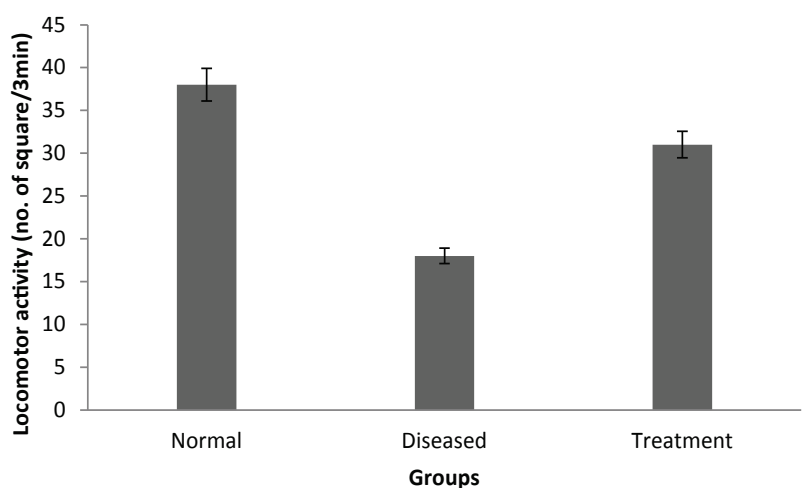

Fig. 4: Locomotor activity score

TABLE 4: PHARMACOKINETIC PARAMETERS

\begin{tabular}{lcc}
\hline Parameters (unit) & Pure DMF & $\begin{array}{c}\text { DMF-loaded CS DS } \\
\text { nanoparticles }\end{array}$ \\
\hline $\mathrm{C}_{\max }(\mathrm{ng} / \mathrm{ml})$ & 1054.51 & 1290 \\
$\mathrm{~T}_{\text {max }}(\mathrm{h})$ & 1.58 & 4 \\
$\mathrm{~K}_{\mathrm{E}}\left(\mathrm{h}^{-1}\right)$ & 0.187 & 0.0940 \\
$\mathrm{~K}_{\mathrm{a}}\left(\mathrm{h}^{-1}\right)$ & 1.28 & 5.80 \\
$\mathrm{t}_{1 / 2}(\mathrm{~h})$ & 3.5 & 7.37 \\
{$[\mathrm{AUC}]_{0}^{\infty}(\mathrm{ng} / \mathrm{ml} . \mathrm{h})$} & 7398.84 & 18528.5 \\
{$[A U M C]_{0}^{\infty}\left(\mathrm{ng} / \mathrm{ml} . \mathrm{h}^{2}\right)$} & 94249.66 & 335625.24 \\
MRT $(\mathrm{h})$ & 12.74 & 18.114 \\
\hline
\end{tabular}

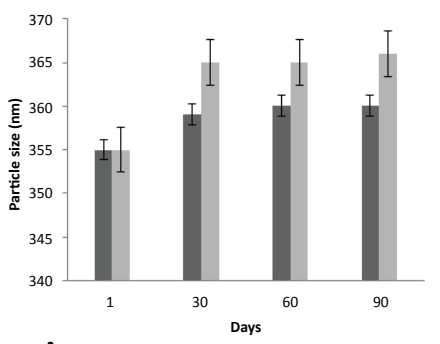

A

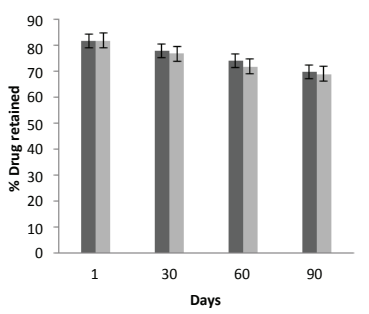

B
Fig. 5: Effect of storage time on (A) particle size and (B) \% drug retained

(घ) $2-8^{\circ},(\varpi) 28 \pm 4^{\circ}$

life was also found to be increased 4 folds in the present nanocolloids providing a higher systemic bioavailability.

The stability study results of nanoparticles are depicted in the fig. 5A and B. There was almost negligible changes in the parameters of z-average and \% drug content with storage at $28^{\circ}$ for $90 \mathrm{~d}$. From the result of stability study it could be noted that the present formulation is stable on storage. The neuroprotective 
ability of developed polymeric nanoparticles was studied on SH-SY5Y cells and was further evaluated to access its pharmacodynamic potential using cuprizone model of Wistar rats and the formulation has proved its neuroprotective potential.

\section{Acknowledgements:}

The authors would like to thank CDRI, Lucknow for providing FTIR spectra, and Aakaar Biotechnology Pvt. Ltd., for conducting MTT assay. They also thank Vishveshwarya Group of Institutions for providing all the facilities needed for this study.

\section{Conflicts of interest:}

The authors declare that there is no conflict of interest.

\section{REFERENCES}

1. Stangel M. Neuroprotection and neuroregeneration in multiple sclerosis. J Neurol 2008;255:77-81.

2. Calabresi PA. Diagnosis and management of multiple sclerosis. Am Fam Physician 2004;70(10):1935-44.

3. Lucchinetti C, Nruck W, Parisi J, Scheithaue BR, Rodriguez M, Lassmann H. Heterogeneity of multiple sclerosis lesions: Implications for the pathogenesis of demyelination. Ann Neurol 2000;47(6):707-17.

4. Krensky AM, Vincenti F, Bennett WM. Immunomodulators; Immunosuppressants, Tolerogens, and Immunostimulants. In: Brunton LL, Lazo JS, Parker KL, editors. Goodman \& Gilman's The Pharmacological Basis of Therapeutics. 11th ed. New York: McGraw-Hill Medical; 2005. p. 1424-7.

5. Beck RW, Cleary PA, Trobe JD, Kaufman DI, Kupersmith MJ, Paty DW, et al. The effect of corticosteroids for acute optic neuritis on the subsequent development of multiple sclerosis. N Engl J Med 1993;329(24):1764-9.

6. Ben-Hur T. Immunomodulation by neural stem cells. J Neurol Sci 2008;265(1-2):102-4.

7. Schweckendiek W. Treatment of psoriasis vulgaris. Med Monatsschr 1959;13(2):103-4.

8. Moharregh-Khiabani D, Linker RA, Gold R, Stangel M. Fumaric Acid and its esters: An emerging treatment for multiple sclerosis. Curr Neuro Pharmacol 2009;7(1):60-4.

9. Fox RJ, Miller DH, Phillips JT, Hutchinson M, Havrdova E, Kita M, et al. Confirm Study Investigators. Placebocontrolled phase 3 study of oral BG-12 or glatiramer in multiple sclerosis. N Engl J Med 2012;367(12):1087-97.

10. Gold R, Giovannoni G, Phillips JT, Fox RJ, Zhang A, Meltzer $\mathrm{L}$, et al. Efficacy and safety of delayed-release dimethyl fumarate in patients newly diagnosed with relapsing-remitting multiple sclerosis (RRMS). Mult Scler 2015;21(1):57-66.

11. Phillips JT, Fox RJ. BG-12 in multiple sclerosis. Semin Neurol 2013;33(1):56-65.

12. Smriti O, Babita K. A review on nanotechnology based innovations in diagnosis and treatment of multiple sclerosis. J Cell Immunol 2018;4(2):56-64.

13. Linker RA, Gold R. Dimethyl fumarate for treatment of multiple sclerosis: mechanism of action, effectiveness, and side effects. Curr Neurol Neurosci Rep 2013;3(11):394.
14. Li J, Calkins MJ, Johnson DA, Johnson JA. Role of Nrf2-dependent ARE-driven antioxidant pathway in neuroprotection. Methods Mol Biol 2007;399:67-78.

15. Constantinescu CS, Gran B. Multiple sclerosis: autoimmune associations in multiple sclerosis. Nat Rev Neurol 2010;6(11):591-2.

16. Zahran M, El-Kemary M, Khalifa S, El-Seedi H. Spectral studies of silver nanoparticles biosynthesized by Origanum majorana. Green Processing Synth 2018;7(2):100-5.

17. El-Kemary M, Ibrahim E, A-Ajmi MF, Khalifa SAM, Alanazi $\mathrm{AD}$, Hesham R. Calendula officinalis-mediated biosynthesis of Silver Nanoparticles and their Electrochemical and Optical Characterization. Int J Electrochem Sci 2016;11,10795-805.

18. Hu FQ, Meng P, Dai YQ, Du YZ, You J, Wei XH, et al. PEGylated chitosan-based polymer micelle as an intracellular delivery carrier for anti-tumor targeting therapy. Eur J Pharm Biopharm 2008;70(3):749-57.

19. Kossena GA, Boyd BJ, Porter CJH, Charman WN. Separation and characterization of the colloidal phases produced on digestion of common formulation lipids and assessment of their impact on the apparent solubility of selected poorly water-soluble drugs. J Pharm Sci 2003;92(3):634-48.

20. Muthu MS, Rawat MK, Mishra A, Singh S. PLGA nanoparticle formulations of risperidone: preparation and neuro pharmacological evaluation. Nanomedicine 2009;5(3):32333.

21. Ojha S, Kumar B. Formulation and optimization of chitosan nanoparticles of dimethyl fumarate using boxBehnken design. Int J Appl Pharm 2016;8(4):10-17.

22. Bhatt $\mathrm{P}$, Khatri N, Kumar M, Baradia D, Misra A. Microbeads mediated oral plasmid DNA delivery using polymethacrylate vectors: an effectual groundwork for colorectal cancer. Drug Deliv 2015; 22(6):849-61.

23. Li S, Yunna C, Yali Z, Dongdong G, Yufan F, Fangyan G, et al. Preparation of 5-fluorouracil-loaded chitosan nanoparticles and study of the sustained release in vitro and in vivo. Asian J Pharm Sci 2017;12(5):418-23.

24. Patel J, Amrutiya J, Bhatt P, Javia A, Jain M, Mishra A. Targeted delivery of monoclonal antibody conjugated docetaxel loaded PLGA nanoparticles into EGFR overexpressed lung tumor cells. J Microencapsul 2018;35(2):204-17.

25. Seju U, Kumar A, Sawant KK. Development and evaluation of olanzapine-loaded PLGA nanoparticles for nose to brain delivery: In vitro and in vivo studies. Acta Biomater 2011;7(12):4169-76.

26. Chetan Y, Dipesh B, Sushil KP, Priyanka B, Jitendra A, Ravi G. Docetaxel loaded immunonanoparticles delivery in EGFR overexpressed breast carcinoma cells. J Drug Deliv Scid Technol 2018;45:334-45.

27. Chang-KS, Ji-Eun C. Potential of nano carriers as cancer cell-specific drug delivery systems in photodynamic therapy. Asian J Pharm Sci 2016;11(1):8-9.

28. Sushilkumar P, Rohan L, Priyanka B, Imran V, Vivek P, Hinal $\mathrm{P}$, et al. Linear Polyethyleneimine for siRNA Delivery: Simple Modification to Overcome Poor Buffer Capacity, Toxicity and Transfection Efficiency. RSC Adv 2018;8(62):35461-73.

29. Ting Y, Lingzhen Q, Zhouhua W, Jinyuan N, Zhefei G, Ge $\mathrm{L}$, et al. Solid lipid dispersion of calcitriol with enhanced dissolution and stability. Asian J Pharm Sci 2013;8(1):39-47.

30. Benjamin NTL, Ling APK, Koh RY, Chye SM, Wong YP. Neuroprotective effects of orientin on hydrogen peroxide- 
induced apoptosis in SH-SY5Y cells. Mol Med Rep 2014;9:947-54.

31. Mosmann T. Rapid colorimetric assay for cellular growth and survival: application to proliferation and cytotoxicity assays. J Immunol Methods 1983;65(1-2):55-63.

32. Love S. Cuprizone neurotoxicity in the rat: morphologic observations. J Neurol Sci 1988;84:223-37.

33. Silvestroff I, Bartucci S, Pasquini J, Franco P. Cuprizoneinduced demyelination in the rat cerebral cortex and thyroid hormone effects on cortical remyelination. Exp Neurol 2012;235:357-67.

34. Song SY, Kato C, Adachi E, Moriya SA, Inagawa OM, Umeda $\mathrm{R}$, et al. Expression of an Acyl-CoA Synthetase, lipidosin, in astrocytes of the murine brain and its up-regulation during remyelination following cuprizone-induced demyelination. J Neurosci Res 2007;85:3586- 97.

35. Franco-Pons $\mathrm{N}$, Torrente $\mathrm{M}$, Colomina MT, Vilella E. Behavioral deficits in the cuprizone-induced murine model of demyelination/remyelination. Toxicol Lett 2000;169(3):20513.
36. Gennari O, Montesano D, Salzano A, Albrizio S, Grumetto L. Determination of dimethyl fumarate in desiccant and antimould sachets by reversed-phase liquid chromatography. Biomed Chromatogr 2011;25:1315-8.

37. Torkildsen O, Brunborg LA, Myhr KM, Bo L. The cuprizone model for demyelination. Acta Neurol Scand Suppl 2008;188:72-6.

38. Ojha S, Kumar B. In vitro and In vivo neuroprotective study of solid lipid nanoparticles loaded with dimethyl fumarate. Asian J Pharm 2018;12(1):S81-S86.

39. Priyanka B, Rohan L, Imran B, Sushilkumar P, Jitendra A, Ambikanandan M, et al. Liposomes encapsulating native and cyclodextrin enclosed Paclitaxel: Enhanced loading efficiency and its pharmacokinetic evaluation. Int J Pharm 2018;536:95107.

40. Chen Y, Mohanraj VJ, Wang F, Benson HA. Designing chitosan-dextran sulphate nanoparticles using charge ratios. AAPS PharmSciTech 2007;8(4):E98.

41. Ojha S, Kumar B. Preparation and statistical modeling of solid lipid nanoparticles of dimethyl fumarate for better management of multiple sclerosis. Adv Pharm Bull 2018;8(2):225-33. 